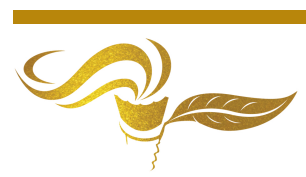

\title{
The COVID-19 Crisis and Complexity in the United States
}

\section{Advisors: A. Ertas and U. Gulbulak Students: K. Basel, M. Campos, G. Handley, D. Hebert, E. Melendez, F. Onatoye, O. Phearum, S. Sawadogo, J. Steckbeck, G. Tekell}

Department of Mechanical Engineering, Texas Tech University, Lubbock Texas, 79409, Email: utku.gulbulak@ttu.edu

Received 29 December, 2020; Revised 3 March, 2021; Accepted 4 March, 2021

Available online 4 March, 2021 at www.atlas-journal.org, doi: 10.22545/2020/00157

\begin{abstract}
T he main objective of this research is to present a transdisciplinary research process which identifies the complexity of the issues surrounding COVID-19 using collective intelligence through transdisciplinary collaborative effort. Interpretive Structural Modeling (ISM), a methodology for dealing with complex system design and development has been the key component of this research. Building collective intelligence to understand how factors affecting COVID-19 transmission and fatality and their relationships were investigated. Two different approaches were used to describe the complexity of the COVID-19 issue. (a) the Situation Complexity and (b) Cyclomatic complexity. The results showed that the complexity of the COVID-19 is difficult to understand and handle.
\end{abstract}

Keywords: Transdisciplinary, COVID-19, complexity of the pandemic, cyclomatic complexity.

\section{Introduction}

First identified in Wuhan, China, in December 2019, the coronavirus disease 2019 (COVID-19) pandemic has resulted in over 20.9 million cases and over 350 thousand deaths in the United States (U.S.) as of January 5, 2021. The U.S., one of the biggest superpowers in the world, quickly became the epicenter for the COVID-19 pandemic. Whether people are aware of it or not, the virus has affected almost every part of their lives- many lost their jobs, mental health had been negatively impacted, healthcare workers, specifically, have been put under copious amounts of stress due to the added COVID-19 patients. They also faced many supply shortages, in particular, blood shortages due to social distancing and the public's fear of the virus.

The pandemic caused a significant negative impact on supply chains and disrupted many industries in the U.S. as well as around the world. The oil and gas sector was severely affected by the pandemic. With the sudden drop in demand for oil, largely due to travel restrictions and shutdowns, the oil and gas industry saw some of the biggest losses it has seen in decades. Retail, travel, and tourism were faced with extraordinary situations that have crippled them. Several small businesses such as accommodations, food service, and educational services are closed because of the changes in customer behaviors, in particular, the physical distancing and mandated operational restrictions - recovery of those businesses may take years or many of them may never reopen [1]. 
A. Ertas, U. Gulbulak, K. Basel, M. Campos, G. Handley, D. Hebert, E. Melendez, F. Onatoye, O. Phearum, S. Sawadogo, J. Steckbeck, G. Tekell

The COVID-19 Crisis and Complexity in the United States

The COVID-19 pandemic is a transdisciplinary societal challenge that requires collective intelligence and coordinated systemic thinking in the context of uncertainty-it is an example of complexity in action. ${ }^{1,2}$

"Effective responses to the complexity, emergence and uncertainty of coronavirus SARSCoV2 and the compound nature of health, economic and social impacts of COVID-19 require understanding and implementing the virtuous relations between disciplinary knowledge and professional know-how, several types of resources, coordinated multi-level governance, and individual and collective behaviors that should be combined in transdisciplinary contributions." 2

Roderick J. Lawrence, 2020

Important factors affecting COVID-19 transmission and fatality appear to include: person to person contact, behavioral risk, indirect transmission, underlying health conditions, worldwide traveling, economic dimension, availability of testing, and government regulations.

\section{Method}

This section aims to discuss how the aforementioned factors affecting COVID-19 relate and interact with one another using Interpretive Structural Modeling (ISM). ISM is a methodology for handling and decomposing complex problems. Proposed by Warfield in $1973 .{ }^{3}$ ISM identifies and reviews relationships among identified parameters. It provides a fundamental understanding of how those parameters are relevant to the complex issue. Thus, it helps researchers to structure complex issues such as COVID-19 in a meaningful way to overcome challenging problems. ${ }^{4}$

\subsection{Context}

Transdisciplinary Collective Intelligence: ISM methodology implementation against this problem consisted of a group of 32 undergraduate students in senior design class, all pursuing Mechanical Engineering degree at Texas Tech University, one Ph.D. student, and one faculty member. This student research team recognized the significant challenges and related countermeasures of COVID-19. They sought to identify the main factors affecting the issues surrounding COVID-19 and how they were interrelated to improve the rate of success to reduce the transmission and fatality.

\subsection{Process}

Understanding of COVID-19 is evolving and requires transdisciplinary collaboration among, and within, institutional sectors to manage the complexity and prevention of COVID-19. Partnering must occur between organizations such as health-care organizations, social services, education, government, community-based organizations, and others. For this research purposes, some (limited) evidence-based information were produced from the aforementioned organization by the advisor of the student research team. The student research team developed transdisciplinary collective intelligence using the Interactive Collective Intelligence Management (ICIM) workshop to investigate the issue. (1) The Nominal Group Technique (NGT) was used to develop and clarify a list of main factors affecting the complex issue ${ }^{5},(2)$ ISM process was used to develop:

\footnotetext{
${ }^{1}$ Lawrence, J. R. Deciphering interdisciplinary and transdisciplinary contributions. Transdisciplinary Journal of Engineering \& Science, Vol. 1, pp. 111-116, 2010.

${ }^{2}$ Lawrence, J. R., (2020). Responding to COVID-19: What's the Problem? J Urban Health, The New York Academy of Medicine, https://doi.org/10.1007/s11524-020-00456-4.

${ }^{3}$ J. N. Warfield, (1974). Developing Interconnected Matrices in Structural Modeling.IEEE Transactions onSystems, Man and Cybernetic, 4(1), pp 51-58.

${ }^{4}$ Ertas A. (2016). Transdisciplinary Trans-Sector Integration in Education: Convergence.TransdisciplinaryJournal of Engineering \& Science, Vol. 7, pp. 55-68.

${ }^{5}$ Delbecq, A. L.; VandeVen, A. H (1971). A Group Process Model for Problem Identification and Program Planning.Journal of Applied Behavioral Science.7, pp. 466-91. doi:10.1177/002188637100700404
} 
1. Structural self-interaction matrix

2. Final reachability matrix

3. Digraph

4. MICMAC Analysis

The student research team identified eight factors for how to handle complex issues of COVID-19. The factors were grouped into four levels. Through MICMAC analysis, it was shown how these factors are interrelated and how the results of MICMAC analysis could help to manage the complexity and prevention of COVID-19. (see Figure 1 for Sequence of activities to develop an ISM model).

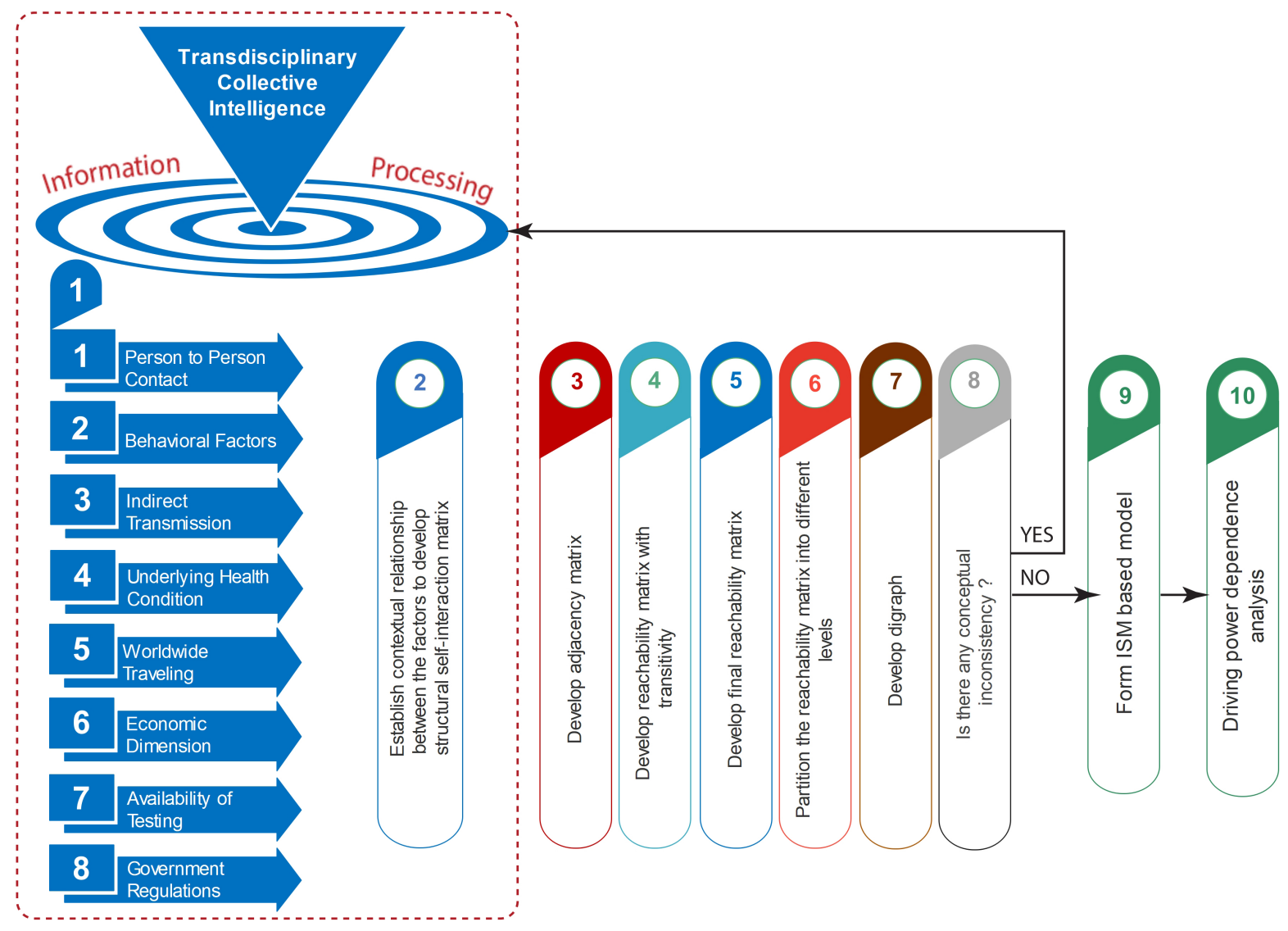

Figure 1: Sequence of activities to develop an ISM model.

\subsection{Content}

The student research team developed a set of factors hypothesized to be affecting the complexity of COVID19 showing how the identified factors were related to each other. The ICIM workshop was facilitated by a $\mathrm{PhD}$ student, who is familiar with the concept.

\subsection{Identifying Factors}

During the first stage of the ICIM workshop, through group brainstorming, potential factors that affect the successful management of the complexity and prevention of COVID-19 were identified. The research team 
A. Ertas, U. Gulbulak, K. Basel, M. Campos, G. Handley, D. Hebert, E. Melendez, F. Onatoye, O. Phearum, S. Sawadogo, J. Steckbeck, G. Tekell

The COVID-19 Crisis and Complexity in the United States

developed twenty four factors affecting the COVID-19.

\subsection{Structuring the Factors}

After three organized ICIM workshops, the student research team determined which factors were most important. From the set of twenty four factors, the following subset of eight, namely underlying health conditions, behavioral factors, indirect transmission, worldwide traveling, government regulations, availability of testing, economic dimension, and person to person contact, was structured using the methodology of ISM. Those were the ones receiving the highest scores in voting on the most important main factors.

\section{Important Factors Affecting COVID-19 Transmission and Fatality}

\subsection{Underlying Health Conditions}

Individuals that have underlying health conditions are the most susceptible to experiencing a significant ailment upon contracting COVID-19. Many conditions can cause an increased risk of severe illness, including coronary artery disease, active cancer, obesity, sickle cell disease, type1 and type 2 diabetes mellitus, chronic kidney disease, asthma, cystic fibrosis, high blood pressure, and liver disease [2]. A large amount of the world population is at an increased risk of developing harmful and potentially life-threatening symptoms upon contracting COVID-19. According to a study done in 188 countries, it is estimated that approximately $22 \%$ of people worldwide have an underlying health condition [3].

Individuals with underlying conditions have been advised to take additional precautionary measures to limit their exposure to others, and likewise, to COVID-19 due to the severity of the symptoms [4]. An example of extra precautionary measures to avoid contracting COVID-19 is strict self-isolation. Though this is recommended for the sake of the physical health and well-being of people in almost every society, some negative ramifications accompany it. Studies have shown that people have felt increasing loneliness since the pandemic began $[5,6]$. This shows that strict recommendations that are set to help individuals with underlying conditions come with the cost of impacting other areas of an individual's or society's well-being.

Another important factor is the immune response to COVID-19. Each individual's immune system responds differently to the disease. Some people may contract the virus and not realize it, while others may contract it and suffer greatly. Since COVID-19 is a relatively new virus, there are still many unknowns, particularly related to the immune response to the virus. One thing which is known is that patients antibodies against COVID-19 were found in the blood of recovered patients and the antibodies can last up to 7 months. 67 Generally, antibodies help to prevent people from getting the same infection, but there is not currently enough data to prove that antibodies protect people from COVID-19.

A case currently being studied is the linkage between plasma gelsolin levels and the COVID-19 mortality rate. Plasma gelsolin is a protein with anti-inflammatory properties, and individuals with lower levels of plasma gelsolin, who suffered from serious cases of pneumonia. ${ }^{8}$ Low levels of gelsolin may also correlate to a high mortality rate due to COVID-19, and gelsolin levels are currently being studied in patients to see if there is a relationship between gelsolin and the severity of the disease symptoms.

\subsection{Behavioral Factors}

Behavioral factors like social distancing, wearing masks and avoiding large gatherings prove to be an effective combatant towards transmission. Physical distancing is very effective in preventing transmission. Chu et al. [7] 16 countries and 172 studies. There is a significant decrease in transmission with physical

\footnotetext{
${ }^{6}$ https://www.who.int/docs/default-source/coronaviruse/risk-comms-updates/update-34-immunity-2nd.pdf?sfvrsn= 8a488cb6_2\#: :text=For\%20COVID\%2D19\%2C,long\%20protection $\% 20$ will\%20last.

${ }^{7}$ https://www.cidrap.umn.edu/news-perspective/2020/10/studies-show-long-term-covid-19-immune-response

${ }^{8}$ https://www.niaid.nih.gov/research/immune-response-covid-19
} 
distancing of 1 meter, and risk protection continues to increase with distance. Even greater benefits arise at 2 meters, correlating with six-foot (approximately 1.83 meters) social distancing policies. This was determined through a pooled adjusted odds ratio in which 25,697 individuals were observed. Absolute risk percentage is exponentially decreasing with distance. Within a $95 \%$ confidence interval, absolute risk percentage is cut in half at one meter. At two meters the absolute risk is drastically reduced. Although distancing is effective, it is not the only tool in fighting transmission.

Mask use is a key behavioral factor in slowing the spread of the COVID-19. The importance of wearing masks is emphasized [8]. Masks prevent droplet spreading and transmission. In a study of 12,710 samples, proper face covers reduce the risk of respiratory infection by as much as $20 \%$. In addition, public mask usage was given an odds ratio of 0.36 in a 2004 Hong Kong Study [8]. Odds ratio associates outcome with a comparison group. A low ratio indicates a decrease in risk of transmission. Through proper supply and emphasis, masks present a cost-effective reduction in infection.

Large gatherings greatly promote transmission of COVID-19. Transmission at these gatherings is reliant on: size, type of gathering, and the COVID-19 precautions taken [9]. These results suggest the reproduction number, $(R o)$. Reproduction number is a way to estimate how contagious the virus can be in different situations. COVID-19 is unique in the fact that "superspreaders" raise its reproduction number. A high $R o$ value represents a greater risk. While one infected individual might refrain entirely from spreading the virus, a "superspreader" could drastically increase the Ro value. A mathematical model was created that relates the infection rate $(r i)$, reproduction number $(R o)$, and the incubation period $(N)$. Many gathering events were taken into account, and guests were split into susceptible and infected individuals. Using this mathematical model, very accurate case numbers are estimated. This is a useful prediction tool, and helpful for contract tracing. In general, weddings were estimated at a Ro value of 5 [9]. This is supported by case studies based in Jordan and Uruguay. Specifically, the 500-guest wedding in Uruguay directly produced 44 cases. This is assumed to be induced by several infected guests entering from Spain. As a whole, Uruguay's positive cases rose from 4 to 79 in a course of 8 days [10]. Similarly, religious gatherings estimated a Ro value of 2.5 [9]. Gatherings in South Korea and Malaysia supported this model. In the Malaysian study, approximately 10,500 attendees were present at Tablighi Jamaat. The event occurs in close proximity and involves both hand-holding and the sharing of food. As a result, 620 tested positive for COVID-19 in both Malaysia and surrounding countries, making it the largest transmission center in South-East Asia [11]. Although certain precautions may be taken, it is clear to see the negative impacts of large social gatherings. Maintaining behavioral factors is the most effective defense against COVID-19 until a sustainable vaccine is produced.

\subsection{Indirect Transmission}

The SARs-CoV-2 has been shown to still be detectable on non-porous surfaces, including stainless steel, glass, and paper bills, for at least 28 days at ambient temperature and humidity [12]. Low temperature and proper relative humidity are associated with the longer persistence of the virus. Public surfaces that require contact to operate, like door handles or touchscreens, can act as vectors for the virus for days or weeks after initial contact [13]. Simple disinfection procedures can cause no infectious virus to be detected after 5 minutes. Exposure to UVB in sunlight, 290-315 nm, can inactivate the virus on surfaces. Outdoor surfaces that are exposed to the sunlight, such as park benches or uncovered tables, will become relativity virus-free in short periods from Spring to Autumn. Sunlight does not instantaneously inactivate the virus; at least 10 minutes of exposure is needed for inactivation [14]. Transmission via indirect contact with surfaces exposed to the virus must be considered when dealing with the spread of COVID-19.

It has been shown that airborne transmission of SARS-CoV-2 can occur without direct contact with an infected individual. The virus has been detected in the air for at least 30 minutes in enclosed spaces and spaces with poor ventilation [15]. Public transportation, particularly buses and trains, represents elevated risk areas for airborne transmission [16]. The widespread use of face coverings has reduced the risk of indirect airborne transmission. 
A. Ertas, U. Gulbulak, K. Basel, M. Campos, G. Handley, D. Hebert, E. Melendez, F. Onatoye, O. Phearum, S. Sawadogo, J. Steckbeck, G. Tekell

The COVID-19 Crisis and Complexity in the United States

\subsection{Worldwide Traveling}

The global transmission of COVID-19 is associated with international travel and business operations. The SARS-CoV-2's capability to be transmitted across the world is partly why it is such a distressing problem to tackle. The earliest documented cases of the outbreak have been linked to the city of Wuhan in China. However, due to the high infection rate, it has spread to hundreds of countries around the world [17]. There are multiple factors that affect the global transmission of COVID-19 including the health of travelers, the regulations for travel, and indirect transmission.

One of the main factors involved in the global transmission of the COVID-19 virus is travel by people who had been exposed to the virus. The symptoms of COVID-19 usually take 2-14 days to appear, making it difficult to monitor and address early on. Furthermore, many of those infected are asymptomatic, meaning that they do not exhibit the symptoms associated with the virus. This makes it easy for hosts to infect those that they come in contact with. Due to the nature of mass transport, travelers that have contracted SARS-CoV-2 pose a high risk of infecting the people they share a trip with. Mass transport systems such as planes and trains are of particular concern, as passengers are placed in close proximity where the virus may be passed directly through respiratory droplets. The virus may have originated in the city of Wuhan, but quickly spread to Italy and eventually throughout the globe because of air travel by passengers that were already hosts for the virus [17].

Another important factor concerning global transmission is the regulations implemented on international travel. Soon after reports of the outbreak were broadcast, countries began to implement regulations to minimize the spread of the virus internationally. 59 countries have opted to close their border to international travelers, meaning that only citizens and residents may enter the country without the presence of special circumstances [18]. While the immediate response to the pandemic was to ban international travel to and from countries that were identified as centers for the disease, more regulations were introduced to allow individual countries control over how they planned to address the pandemic. Regulations to minimize the spread now include temperature checks at the airport, required 14-day quarantines upon arrival into some countries, and even COVID-19 test results in some cases [19]. Being able to build and maintain business with multiple countries is essentially important for the survival of many nations, as the global trade and shipping routes enable access to resources that they otherwise would not be able to attain. Limitations on shipments for extended periods can lead to devastating consequences such as the inability to import food and water. Therefore, most countries have opted to continue trading at a slower pace, while adhering to the new regulations being enforced [20].

Lastly, the SARS-CoV-2's ability to be transmitted indirectly also contributes to its global transmission. Indirect transmission with respect to global travel includes touching previously contaminated areas, as well as sharing food or drinks with someone who is contaminated. The virus is resilient enough to survive for 5 days on certain surfaces such as metal or glass, which allows it to be passed on from hosts long after they have departed the contaminated area [21]. While not as common as direct transmission of the virus, airports and businesses have made efforts to clean common use areas multiple times a day to minimize the chances of infection.

Living in modern society allows us to explore foreign countries, enjoy the benefits of international trade and attain an interconnected global economy. However, it also allows the virus to easily spread across the world. To minimize the global spread of COVID-19, government agencies, international businesses, and healthcare experts must be aligned in their mission for a safe method of travel and commerce.

\subsection{Government Regulations}

The first case of COVID-19 was reported in China in November 2019. In March of 2020 the World Health Organization declared COVID-19 as a pandemic. At this point, it forced governments to quickly create regulations and laws for the safety of their citizens. Within the first six months, the spread of COVID-19 reached 188 countries and killed hundreds of thousands of individuals [22]. Due to the rapid spread of COVID-19, different policy responses were used within countries around the world. These policy responses were put in place to limit the spread and assist the burden on health systems [23]. In Asia and Southern 
Europe, very drastic approaches were implemented, whereas places such as Sweden were found to be less strict and more flexible [23]. Governments must take into consideration how individuals would adjust to the information based on the regulations put in place. It has been shown that individuals respond in a rational approach, by making behavioral adjustments and thinking more carefully about their choices when individuals know all of the health risks. However, a negative drawback of COVID-19 was how little was known about health risks when the first lock-down was announced [23]. These government regulations around the world included policies that dealt with "international travel controls, cancellation of public events, closing of public transportation, closing of schools, closing of workplaces, and restrictions on internal movements..." [23]. All of these policies were used in hopes of limiting physical contact between individuals by avoiding any social interactions. It is important to notice that there were obvious differences in the speed at which different countries to respond to the pandemic [23].

One of the most common government regulations is putting in places quarantines. A quarantine is when there is a separation between individuals who have been exposed to a contagious disease. This is not to be confused with isolation, which is when there is a separation of individuals who are known to have said disease. Quarantines were seen in China, where whole cities were locked down, in Italy, where restrictions were placed throughout the country, and in the U.S., where thousands of people were placed in quarantines [24]. Quarantines are typically the initial response when new infectious diseases are known. The U.S. government has put in place regulations that include banning entry from non-U.S nationals traveling from China, Iran, and the majority of Europe and screens passengers that return from any heavily affected countries [24]. The U.S. government policies of the travel ban, quarantines, and social distancing are not going to end the outbreak alone. Other policies that have been put in place are the availability of free testing and the ability to allow individuals to work from home. "For individuals who cannot afford to work from home, there is a Families First Coronavirus Response Act which hopes to provide paid sick leave and unemployment insurance..." [24]. Two examples of the more effective government regulations can be stated as "limiting international travel and closure of non-essential workplaces" [22]. An example of a government regulation that had a smaller impact was closing schools [22]. Government regulations are a key part of decreasing social interactions which helps the spread slow down. The main goal is to flatten the curve and reduce transmission of SARS-CoV-2.

\subsection{Availability of Testing}

Most activities are now subjected to COVID-19 testing. For instance, since November 23, travel to Canary Island is subjected to a negative PCR COVID-19 test result taken within 72 hours of arrival [25]. Testing plays an important role in the prevention of COVID-19 transmission. The isolation of infected individuals contributes to the reduction of the spread of the disease and allows contact tracing for people exposed. It provides knowledge of regional and national rates of infection and influences public health interventions [26]. The results of testing are used to construct mathematical models predicting the trend of the disease and provide insight to decision-makers. Unfortunately, some tests seem to be more sensitive to COVID-19 than others. One dramatic example of the failures of airport screening just played out in China, eight Chinese citizens arrived at Shanghai Pudong International Airport on 27 and 29 February they were screened by "non-contact thermal imaging" after taking chartered cars to Lishui, their hometown, one of the passengers fell ill; she was tested positive for COVID-19, on 1 March. The next day, the remaining seven were tested positive as well. They were the first confirmed cases in Zhejiang province in 1 week [27].

In another example, a COVID-19 patient had a nasopharyngeal/oropharyngeal RT-PCR swab that was negative for COVID-19, but RT-PCR of BAL fluid was positive [28]. In another case, a clinical study of 80 patients from the Jiangsu Province who were ultimately diagnosed with COVID-19. Nine of those 80 patients $(11.3 \%)$ had two negative RT-PCR nasal or oral swabs before their third swabs came back positive [28].

While the exact sensitivity and specificity of RT-PCR tests for COVID-19 are not fully known, it appears that a positive test is highly suggestive of true COVID-19, but a negative test does not rule out the disease. In the case of COVID-19 symptoms, it is best to assume that patients have the disease even if 
A. Ertas, U. Gulbulak, K. Basel, M. Campos, G. Handley, D. Hebert, E. Melendez, F. Onatoye, O. Phearum, S. Sawadogo, J. Steckbeck, G. Tekell

The COVID-19 Crisis and Complexity in the United States

their test was negative. The push for increased testing in areas that already have widespread COVID-19 may be overstated, as the benefits of large-scale use of a moderate sensitivity test are minimal [28].

In general, a single negative test result may not be informative if the pre-test probability is high. In some cases, someone with a negative test has a $74 \%$ chance of having COVID-19; with two negative tests, this risk is still around $47 \%$ [26].

A reliable and quicker test seems vital for limiting the spread of COVID-19. The current swab test used in the U.S. and most countries requires a minimum of 24 hours waiting times. During this period, some patients will still go shopping or work, and only then get a positive result, risking the community spread of the virus.

The rapid test allows people to test themselves at home and know the results within minutes. It should be noted that the current at-home test cost around $\$ 150$ at Costco, Walmart, LabCorp, and Quest. The obtention of the results requires 24 to 48 hours waiting time [29]. On November 17 FDA authorizes the Lucira Health's "All-In-One" at-home test. The single-use molecular-based kit developed by California Biotechnology is expected to sell for less than 50 dollars and will be available by spring 2021. The result is available in 30 minutes, but the kit requires a prescription.

Ellume test is expected to cost $\$ 30$ and only requires a smartphone application to learn the results. Another at-home test authorized is BinaxNow from Abbot Laboratories. It cost $\$ 25$ and requires a smartphone app called Navica and guidance from a telehealth company called eMed. Currently, most at-home tests have a reliability of about 90\% [30]. The consequence of a widely available at-home test is that some people will lower their guard relying on the result of testing. They might not socially distance or respect safety measures advised by medical communities and local authorities, which will lead to a spike of contagion.

The availability of vaccines should not shadow the importance of testing as, the period of immunity of vaccines, and the long-term impact of COVID-19 on the body are still not fully known. Moreover, countries with fewer resources will not be able to provide vaccines to their citizen at the same pace as developed countries.

\subsection{Economic Dimension}

Although the COVID - 19 pandemic emerged as a global health crisis, it swiftly became an economic crisis as well [31]. COVID - 19 impacted primary sectors, which deal with the extraction of raw materials, secondary sectors, that are responsible for production, and tertiary sectors, such as aviation, tourism, and sports [32]. Agricultural businesses were affected because of the reduced labor, decrease in necessary inputs and output prices [33]. Additionally, the demand for oil and oil products decreased by $30 \%$ compared to demand in 2019 as a result of the deceleration in production. In the early stages of the pandemic, China stopped all manufacturing operations in order to stop the spread. This action led to scarce supplies of raw materials and spare parts globally [34]. The global efforts to reduce the spread of COVID - 19 led to a drastic decrease in demand for air transportation. The number of commercial flights dropped by $40 \%$ and has not yet recovered [35]. It was predicted that the aviation industry might have lost $\$ 314$ billion in 2020 due to the pandemic as both national and international travel are major parts of the global economy [36]. Due to the concerns related to the pandemic and travel restrictions, global tourism related revenues, such as export from tourism and tourist spending, was reduced by approximately $\$ 1$ trillion [37]. The year of 2020 was an anticipated year for a lot of athletes as the summer Olympics and European soccer championship were scheduled to take place. Hosting Olympic games requires years long preparation and investment by the hosting country. The International Olympic Committee postponed the event to summer 2021. The economic consequences of the postponement were estimated as $\$ 6$ billion for Japan, the hosting country [38]. The Union of European Football Association followed the same approach and decided to postpone the European soccer championship to summer of 2021. Unlike the Olympics, the event would be hosted by 12 different countries. It is estimated that the hosting countries will lose a total of $\$ 327$ million [39]. In addition to the financial problems, the delay will result in scheduling issues to national and international soccer competitions. 


\subsection{Person to Person Contact}

With exponential growth of reported cases of COVID-19 both in the United States and globally, health administrators are focused on reducing the spread. By understanding how the virus is transmitted from one to the other, we can revenue the right steps to slowing the spread. Experts believe COVID-19 spreads mostly from "person to person contact", also called "direct transmission". The transmission occurs when an infected person touches or exchanges body fluids with someone else. There are different forms of direct transmissions such as a droplet, respiratory infections, and airborne transmission. The droplet transmission occurs due to the direct contact with a person with respiratory symptoms or indirect contact through surface or objects [40]. It was observed that the virus can survive on plastic and stainless-steel surfaces for up to 72 hours [41]. High-risk contact occurs when a person lives in the same household with a COVID-19 patient [42]. Medium high-risk contact is frequent contact with people who have recently tested positive for COVID-19 such as a friend, coworker, and classmate. Medium risk contact is close contact with a person positive test of the virus but not regularly meet [42]. Low-risk contact is being in the same indoor setting with a person with symptoms [42]. Non-contact is interaction with a person with a virus, for example, walk by the patient [42].

\section{Interpretive Structural Modelling (ISM) Process}

\subsection{Development of TD collective intelligence}

ISM approach starts with the development of transdisciplinary (TD) collective intelligence which includes identifying main factors affecting the complexity of the issue (Step-1) and the development of the Structural Self-Interaction Matrix (SSIM) (Step-2). This is accomplished by exercising the Interactive Collective Intelligence Management (ICIM) workshop (see Section 2).

\subsection{STEP 2: Structural Self-Interaction Matrix (SSIM)}

After providing clear definitions, the SSIM was used to define the relationship between these factors to determine their effects on one another. As seen from Figure 2, four symbols were used inside the matrix $(\mathrm{A}, \mathrm{V}, \mathrm{X}, \mathrm{O}$ ). A, is entered when the relation is from $\mathrm{j}$ to $\mathrm{i}$. $\mathrm{V}$, is entered when the relation is from $\mathrm{i}$ to $\mathrm{j}$. $\mathrm{X}$, is entered when the relation is both from $\mathrm{i}$ to $\mathrm{j}$ and $\mathrm{j}$ to $\mathrm{i}$. $\mathrm{O}$, is entered when there is no relation at all. The identified factors are assumed to be interrelated, rather than independent: some factors may increase the effects of other factors. Using expert opinions along with the student research team, the SSIM was developed.

As shown in Figure 1, the combination of two steps is called Transdisciplinary Collective Intelligence Development. ${ }^{9}$

\subsection{STEP 3: Development of Adjacency Matrix}

Then the adjacency matrix shown in Figure 3 is developed by transforming SSIM into a binary matrix, by substituting $\mathrm{V}, \mathrm{A}, \mathrm{X}$, and $\mathrm{O}$ by 1 and 0 per the outline described below:

- When the $(i, j)$ entry in the SSIM is $V$, then the $(i, j)$ entry in the reachability matrix becomes 1 and the $(\mathrm{j}, \mathrm{i})$ entry becomes 0 .

- When the (i,j) entry in the SSIM is A, then the (i, j) entry in the reachability matrix becomes 0 and the $(\mathrm{j}, \mathrm{i})$ entry becomes 1.

- when the $(i, j)$ entry in the SSIM is $X$, then both the $(i, j)$ and $(j, i)$ entries of the reachability matrix become 1 .

\footnotetext{
${ }^{9}$ Aldana M. et al., (2019). Just-in-Time Supply Chain Innovation through Additive Manufacturing: A Trans-disciplinary Educational Experience.Transdisciplinary Journal of Engineering \& Science, ISSN: Vol. 10, pp.199-223.
} 
A. Ertas, U. Gulbulak, K. Basel, M. Campos, G. Handley, D. Hebert, E. Melendez, F. Onatoye, O. Phearum, S. Sawadogo, J. Steckbeck, G. Tekell

The COVID-19 Crisis and Complexity in the United States

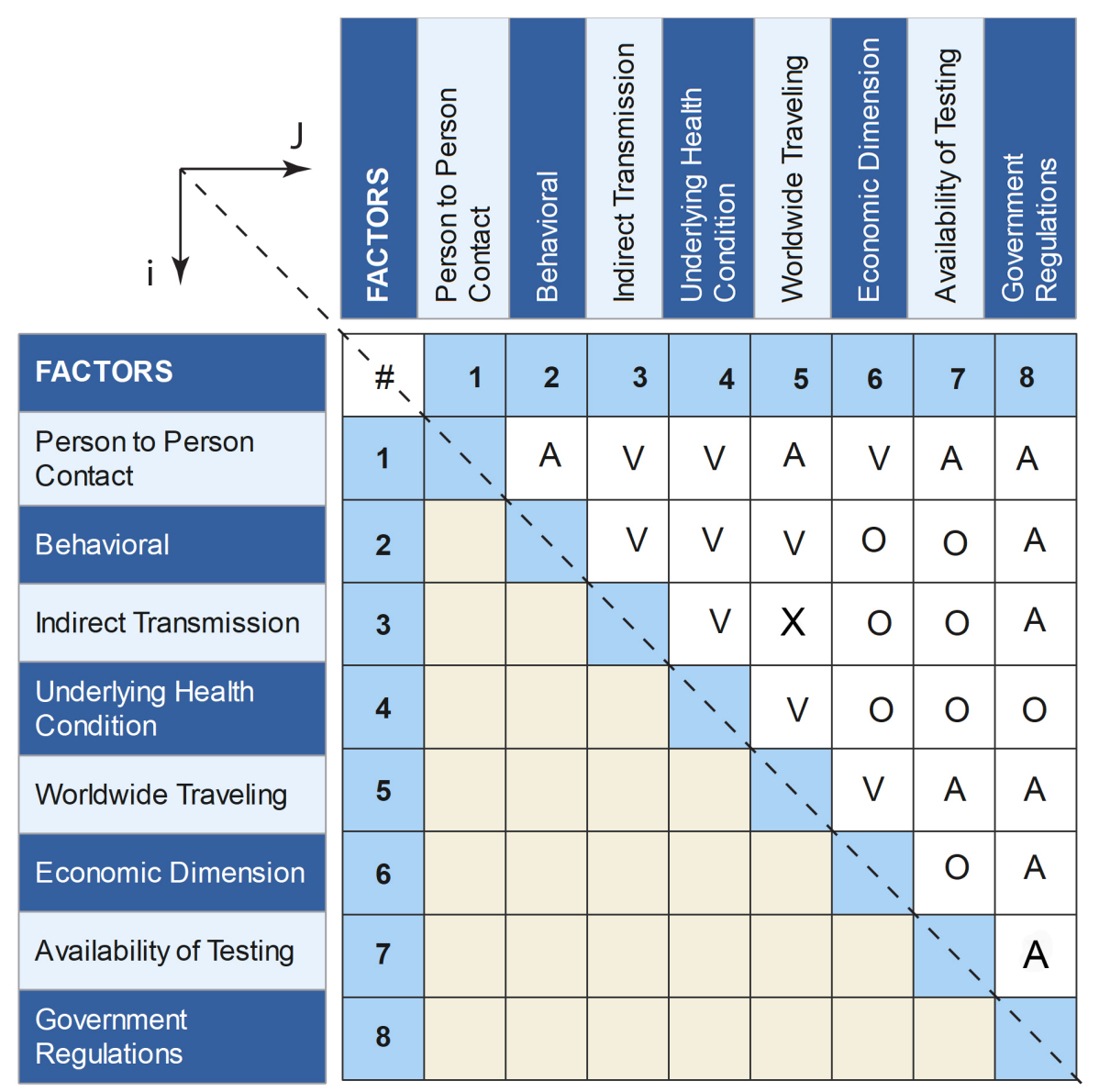

Figure 2: Structural Self-Interaction Matrix (SSIM.

\begin{tabular}{|l|l|l|l|l|l|l|l|l|l|}
\hline FACTORS & $\mathbf{\#}$ & $\mathbf{1}$ & $\mathbf{2}$ & $\mathbf{3}$ & $\mathbf{4}$ & $\mathbf{5}$ & $\mathbf{6}$ & $\mathbf{7}$ & $\mathbf{8}$ \\
\hline Person to Person Contact & $\mathbf{1}$ & 1 & 0 & 1 & 1 & 0 & 1 & 0 & 0 \\
\hline Behavioral & $\mathbf{2}$ & 1 & 1 & 1 & 1 & 1 & 0 & 0 & 0 \\
\hline Indirect Transmission & $\mathbf{3}$ & 0 & 0 & 1 & 1 & 1 & 0 & 0 & 0 \\
\hline Underlying Health Condition & $\mathbf{4}$ & 0 & 0 & 0 & 1 & 1 & 0 & 0 & 0 \\
\hline Worldwide Traveling & $\mathbf{5}$ & 1 & 0 & 1 & 0 & 1 & 1 & 0 & 0 \\
\hline Economic Dimension & $\mathbf{6}$ & 0 & 0 & 0 & 0 & 0 & 1 & 0 & 0 \\
\hline Availability of Testing & $\mathbf{7}$ & 1 & 0 & 0 & 0 & 1 & 0 & 1 & 0 \\
\hline Government Regulations & $\mathbf{8}$ & 1 & 1 & 1 & 0 & 1 & 1 & 1 & 1 \\
\hline
\end{tabular}

Figure 3: Adjacency matrix. 


\begin{tabular}{|l|l|l|l|l|l|l|l|l|l|}
\hline FACTORS & \# & $\mathbf{1}$ & $\mathbf{2}$ & $\mathbf{3}$ & $\mathbf{4}$ & $\mathbf{5}$ & $\mathbf{6}$ & $\mathbf{7}$ & $\mathbf{8}$ \\
\hline Person to Person Contact & $\mathbf{1}$ & 1 & 0 & 1 & 1 & 1 & 1 & 0 & 0 \\
\hline Behavioral & $\mathbf{2}$ & 1 & 1 & 1 & 1 & 1 & 1 & 0 & 0 \\
\hline Indirect Transmission & $\mathbf{3}$ & 1 & 0 & 1 & 1 & 1 & 1 & 0 & 0 \\
\hline Underlying Health Condition & $\mathbf{4}$ & 1 & 0 & 1 & 1 & 1 & 1 & 0 & 0 \\
\hline Worldwide Traveling & $\mathbf{5}$ & 1 & 0 & 1 & 1 & 1 & 1 & 0 & 0 \\
\hline Economic Dimension & $\mathbf{6}$ & 0 & 0 & 0 & 0 & 0 & 1 & 0 & 0 \\
\hline Availability of Testing & $\mathbf{7}$ & 1 & 0 & 1 & 1 & 1 & 1 & 1 & 0 \\
\hline Government Regulations & $\mathbf{8}$ & 1 & 1 & 1 & 1 & 1 & 1 & 1 & 1 \\
\hline
\end{tabular}

Figure 4: Reachability matrix with transivity.

- when the $(i, j)$ entry of the SSIM is $O$, then both the $(i, j)$ and $(j, i)$ entries of the reachability matrix become 0 .

In other words, looking only at the upper right triangle, all the Xs and Vs from the input Figure 2 are recorded as 1s, whereas the As and Os of the upper right triangle have transformed to 0s (zeros). On the other hand, the As are 1s and the Vs are 0s on the lower left triangle.

\subsection{STEP 4: Reachability Matrix with Transitivity}

Figure 4 shows the reachability matrix with transitivity. The reachability matrix is tested for the transitivity rule and is updated until transitivity is confirmed. The transitive rule is "if A has a relationship to B and $\mathrm{B}$ has a relationship to C, then A has relationship to C". In other words, the reachability matrix with transitivity takes the information given in the initial reachability matrix and adds more 1s to represent the indirect relationships between terms. Following the transitivity rule, a reachability matrix shown in Figure 4 is developed.

\subsection{STEP 5: Final Reachability Matrix}

As shown in Figure 5, the row labeled "Dependence" contains summations of ones in each of the columns, and the column labeled "Driving Power" contains summations of ones in each of the rows. The summation in the bottom right corner of the matrix contains a summation total of 41 . This represents the summation of the Driving Power column and the Dependence row. The summation of the column and row is always equal in any reachability matrix with transitivity. Figure 5 is the final form of the relationships of all the factors involved with the problem under consideration. Calculated driving power and dependence in Figure 5 were used for MICMAC analysis.

\subsection{STEP 6 Level Partition:}

The driving force and dependence obtained from the final reachability matrix will help us to classify the factors into groups. These groups are determined by the separation of the antecedent set and the reachability set which will provide an intersection set - the intersection set includes the common factors in 
A. Ertas, U. Gulbulak, K. Basel, M. Campos, G. Handley, D. Hebert, E. Melendez, F. Onatoye, O. Phearum, S. Sawadogo, J. Steckbeck, G. Tekell

The COVID-19 Crisis and Complexity in the United States

\begin{tabular}{|l|l|l|l|l|l|l|l|l|l|l|}
\hline FACTORS & $\#$ & $\mathbf{1}$ & $\mathbf{2}$ & $\mathbf{3}$ & $\mathbf{4}$ & $\mathbf{5}$ & $\mathbf{6}$ & $\mathbf{7}$ & $\mathbf{8}$ & $\begin{array}{c}\text { Driving } \\
\text { Power }\end{array}$ \\
\hline Person to Person Contact & $\mathbf{1}$ & 1 & 0 & 1 & 1 & 1 & 1 & 0 & 0 & 5 \\
\hline Behavioral & $\mathbf{2}$ & 1 & 1 & 1 & 1 & 1 & 1 & 0 & 0 & 6 \\
\hline Indirect Transmission & $\mathbf{3}$ & 1 & 0 & 1 & 1 & 1 & 1 & 0 & 0 & 5 \\
\hline Underlying Health Condition & $\mathbf{4}$ & 1 & 0 & 1 & 1 & 1 & 1 & 0 & 0 & 5 \\
\hline Worldwide Traveling & $\mathbf{5}$ & 1 & 0 & 1 & 1 & 1 & 1 & 0 & 0 & 5 \\
\hline Economic Dimension & $\mathbf{6}$ & 0 & 0 & 0 & 0 & 0 & 1 & 0 & 0 & 1 \\
\hline Availability of Testing & $\mathbf{7}$ & 1 & 0 & 1 & 1 & 1 & 1 & 1 & 0 & 6 \\
\hline Government Regulations & $\mathbf{8}$ & 1 & 1 & 1 & 1 & 1 & 1 & 1 & 1 & 8 \\
\hline Dependence & & 7 & 2 & 7 & 7 & 7 & 8 & 2 & 1 & $\sum \mathbf{4 1}$ \\
\hline
\end{tabular}

Figure 5: Final reachability matrix.

Table 1: Level 1 (first iteration).

\begin{tabular}{|c|c|c|c|c|}
\hline $\begin{array}{c}\text { Factors } \\
\#\end{array}$ & $\begin{array}{c}\text { Reachability } \\
\text { Set }\end{array}$ & $\begin{array}{c}\text { Antecedent } \\
\text { Set }\end{array}$ & $\begin{array}{c}\text { Intersection } \\
\text { Set }\end{array}$ & Level \\
\hline 1 & $1,3,4,5,6$ & $1,2,3,4,5,7,8$ & $1.3,4.5$ & \\
\hline 2 & $1,2,3,4,5,6$ & 2,8 & 2 & \\
\hline 3 & $1,3,4,5,6$ & $1,2,3,4,5,7,8$ & $1,3,4,5$ & \\
\hline 4 & $1,3,4,5,6$ & $1,2,3,4,5,7,8$ & $1,3,4,5$ & \\
\hline 5 & $1,3,4,5,6$ & $1,2,3,4,5,7,8$ & $1,3,4,5$ & \\
\hline 6 & 6 & $1,2,3,4,5,6,7,8$ & 6 & 1 \\
\hline 7 & $1,3,4,5,6,7$ & 7,8 & 7 & \\
\hline 8 & $1,2,3,4,5,6,7,8$ & 8 & 8 & \\
\hline
\end{tabular}

the reachability and the intersection sets. These three sets will help us to identify the levels of the factors. When the factors of the intersection and reachability sets are the same, then that factor will be identified as the top-level group in the ISM hierarchy. Once the top-level factors are identified, they are removed from the set to find the next level. As seen from Tables 1 through 4, this iteration process is repeated until all the levels are identified. These levels will be used to build the digraph.

\subsection{Formation of Digraph}

The digraph is a graphic that shows the direct and indirect relationships between the factors. As shown in Fig. 6, the relationship of sets and binary associations through matrices can now be translated into 
Table 2: Level 2 (second iteration).

\begin{tabular}{|c|c|c|c|c|}
\hline $\begin{array}{c}\text { Factors } \\
\#\end{array}$ & $\begin{array}{c}\text { Reachability } \\
\text { Set }\end{array}$ & $\begin{array}{c}\text { Antecedent } \\
\text { Set }\end{array}$ & $\begin{array}{c}\text { Intersection } \\
\text { Set }\end{array}$ & Level \\
\hline 1 & $13,4,5$ & $1,2,3,4,5,7,8$ & $1,3,4,5$ & $\mathbf{2}$ \\
\hline 2 & $1,2,3,4,5$ & 2,8 & 2 & \\
\hline 3 & $1,3,4,5$ & $1,2,3,4,5,7,8$ & $1,3,4,5$ & $\mathbf{2}$ \\
\hline 4 & $1,3,4,5$ & $1,2,3,4,5,7,8$ & $1,3,4,5$ & $\mathbf{2}$ \\
\hline 5 & $1,3,4,5$ & $1,2,3,4,5,7,8$ & $1,3,4,5$ & $\mathbf{2}$ \\
\hline 7 & $1,3,4,5,7$ & 7,8 & 7 & \\
\hline 8 & $1,2,3,4,5,7,8$ & 8 & 8 & \\
\hline
\end{tabular}

Table 3: Level 3 (third iteration).

\begin{tabular}{|c|c|c|c|c|}
\hline $\begin{array}{c}\text { Factors } \\
\#\end{array}$ & $\begin{array}{c}\text { Reachability } \\
\text { Set }\end{array}$ & $\begin{array}{c}\text { Antecedent } \\
\text { Set }\end{array}$ & $\begin{array}{c}\text { Intersection } \\
\text { Set }\end{array}$ & Level \\
\hline 2 & 2 & 2,8 & 2 & 3 \\
\hline 7 & 7 & 7,8 & 7 & 3 \\
\hline 8 & $2,7,8$ & 8 & 8 & \\
\hline
\end{tabular}

Table 4: Level 4 (fourth iteration).

\begin{tabular}{|c|c|c|c|c|}
\hline $\begin{array}{c}\text { Factors } \\
\#\end{array}$ & $\begin{array}{c}\text { Reachability } \\
\text { Set }\end{array}$ & $\begin{array}{c}\text { Antecedent } \\
\text { Set }\end{array}$ & $\begin{array}{c}\text { Intersection } \\
\text { Set }\end{array}$ & Level \\
\hline 8 & 8 & 8 & 8 & $\mathbf{4}$ \\
\hline
\end{tabular}

graphical form by using the theory of digraphs (directed graphs). ${ }^{10}$ If there is a relationship between factors and $\mathrm{j}$ has impact on $\mathrm{i}$, the connection between factors will go from $\mathrm{j}$ to $\mathrm{i}$ digraph.

\subsection{MICMAC Analysis}

The MICMAC (cross-impact matrix multiplication applied to classification) analysis is used to identify and examine the driving power and the dependence of the particular issues was developed by Duperrin and

\footnotetext{
${ }^{10}$ F. Harary, R. V. Norman and D. Cartwright, Structural Models: An Introduction to the Theory of Directed Graphs, Willey, New York, 1965.
} 


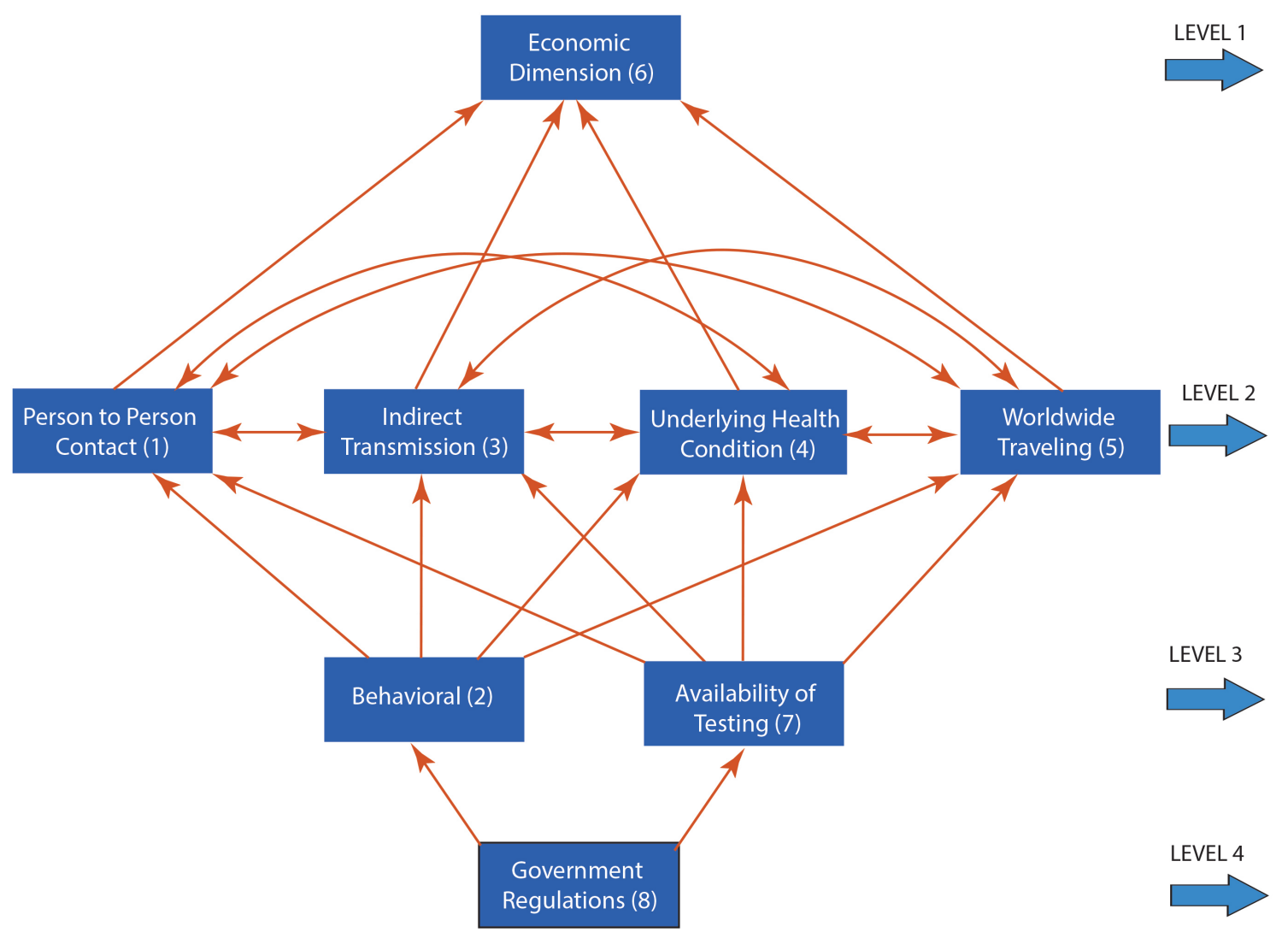

Figure 6: Digraph.

Godet in $1973 .{ }^{11}$ Factors are arranged through MICMAC analysis with respect to their driving power and dependence in four clusters: ${ }^{12}$ (1) autonomous, (2) dependent, (3) linkage, and (4) independent factors. The driving power and dependence of each of the factors are imported from Figure 5. Figure 7 shows the driving power-dependence map for the important factors affecting COVID-19 transmission and fatality.

\section{Discussions}

The main objective of this research is to present a TD research process that identifies the complexity of the COVID-19 using collective intelligence through the transdisciplinary collaborative effort. Interpretive Structural Modeling (ISM), a methodology for dealing with complex system design and development, is the key component of this research. Building collective intelligence to understand how factors affecting COVID-19 transmission and fatality and their relationships are an important part of interpretive structural modeling. After removing the transmissivities based on the reachability matrix as explained in the ISM approach, the digraph (Figure 6) is obtained and finally, the MICMAC analysis was used to identify and examine the driving power and the dependence of the factors related to the COVID-19 issue.

\footnotetext{
${ }^{11}$ J. C. Duperrin and M. Godet, Methode De Hierar Chization des Elements D'um System, Rapport Economique de CEA, 1973, pp.45-51.

${ }^{12}$ A. Mandal and S. G. Deshmukh, Vendor Selection Using Interpretive Structural Modelling (ISM), International Journal of Operations \& Production Management, 14(6), 1994, pp. 52-59.
} 


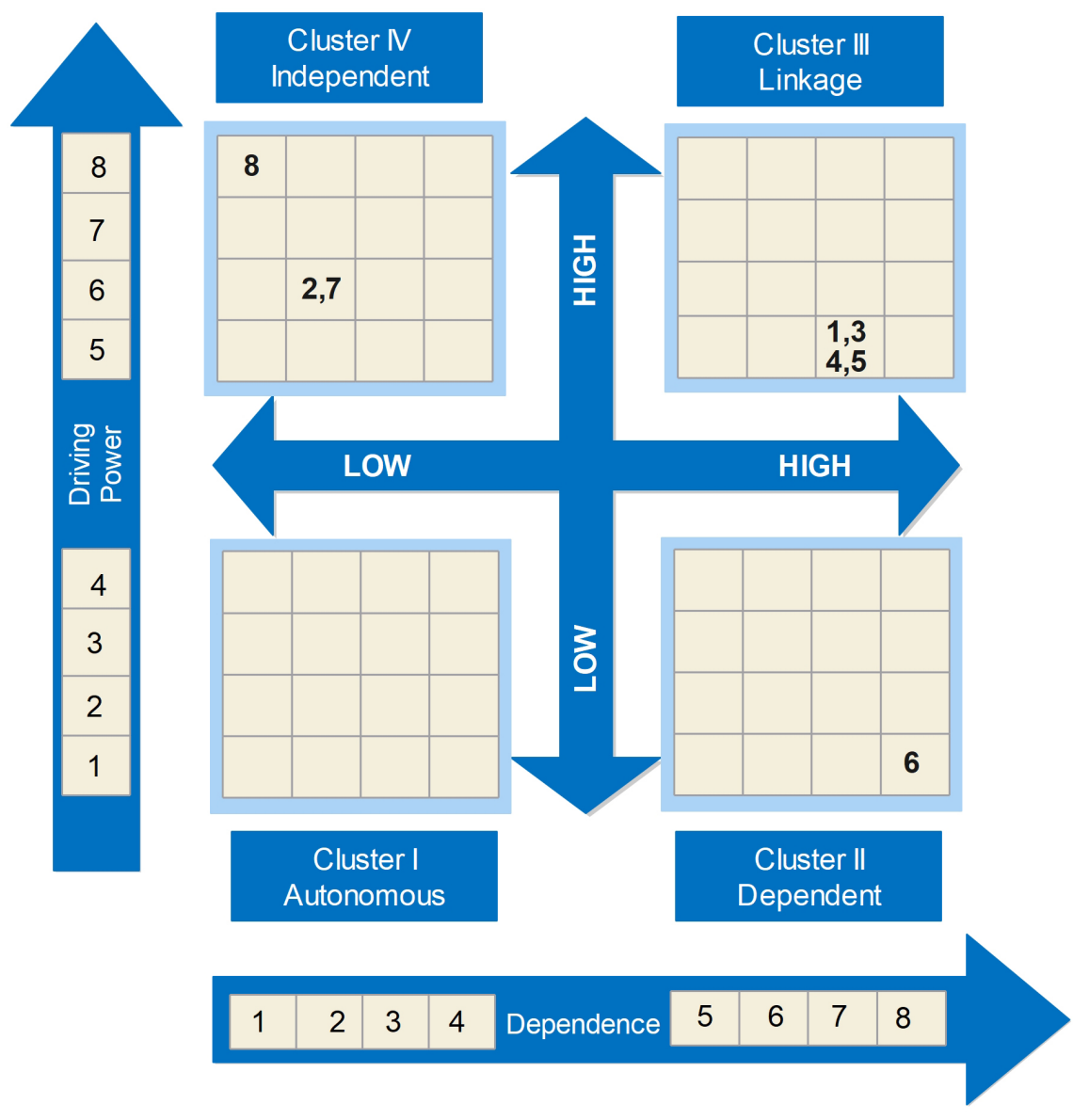

Figure 7: MICMAC Analysis.

\section{Measuring Situational Complexity}

The Situation Complexity Index (SCI) is combined single metric to compare complexity among a group of problematic situations. It is the product of Miller Index, the Spreadthink Index, and the Demorgan Index and defined as: ${ }^{13}$

$$
S C I=\left(\frac{N}{7}\right)\left(\frac{V}{5}\right)\left(\frac{K}{10}\right)
$$

We considered the situation as complex if SCI is over $100 .{ }^{13}$ In Equation (1), (N/7) is known as the Miller Index. Miller discovered the famous "magical number seven, plus or minus two". If the number $\mathrm{N}$ is equal to 7 , the value of the Miller Index will be 1.0 which can be taken as a reference point. For values less than seven, it is assumed that human being is capable of functioning well.

In Equation (1), $(V / 5)$ is identified as the Spreadthink Index. which is a measure of the disagreement among the participant group on the relative importance of the $N$ problems they have generated. In the same equation, $V$ is chosen to be the "selected subset". The NGT voting system accepts each voter to choose confidentially the 5 most important problems as he/she sees significant. If $V=5$, then the spreadthink

\footnotetext{
${ }^{13}$ Warfield, N. J. Understanding Design Science and its Implementation. First World Conference on Integrated Design \& Process Technology, The University of Texas at Austin Texas, 1996.
} 
A. Ertas, U. Gulbulak, K. Basel, M. Campos, G. Handley, D. Hebert, E. Melendez, F. Onatoye, O. Phearum, S. Sawadogo, J. Steckbeck, G. Tekell

The COVID-19 Crisis and Complexity in the United States

index will be equal to 1 - this means that complete consensus achieved. For values greater than 1, Spread Index indicates that the consensus is not achieved - this indicates that complexity is exist.

In Equation (1), the De Morgan Index can be obtained from the simple formula $K / 10$. When the De Morgan Index is 1, it shows that the relationships among problem factors of an issue are acceptable and manageable with usual practices. For values exceeding 1, the De Morgan Index shows that complexity is present.

Beside the student research team, several research engineers from different companies and Local government workers were reached out by the faculty member to discuss the issue of COVID-19.

Through collective research effort, more than seventy five problem areas were identified and twenty four factors affecting the COVID-19 were developed. Eight major problem areas (factors) selected and twenty relationships among the main factors were identified (see Figure 6). Table 5 shows the values of the Miller Index, the Spreadthink Index, and De Morgan Index from ICIM workshop carried out in 2020 Fall semester at the Mechanical Engineering Department.

Table 5: Values of metrics of complexity.

\begin{tabular}{|l|l|l|l|l|}
\hline $\begin{array}{l}\text { Problems } \\
\text { Identified }(\mathbf{N})\end{array}$ & $\begin{array}{l}\text { Problems } \\
\text { Selected }(\mathbf{V})\end{array}$ & $\begin{array}{l}\text { Problems } \\
\text { Structured }\end{array}$ & $\begin{array}{l}\text { Number of } \\
\text { Relationships } \mathbf{( K )}\end{array}$ & $\begin{array}{l}\text { Complexity } \\
\text { Index (SCI) }\end{array}$ \\
\hline 75 & 24 & 8 & 20 & 102.8 \\
\hline
\end{tabular}

$$
S C I=\left(\frac{N}{7}\right)\left(\frac{V}{5}\right)\left(\frac{K}{10}\right)=\left(\frac{75}{7}\right)\left(\frac{24}{5}\right)\left(\frac{20}{10}\right)=102.8
$$

Since the value of SCI is larger than 100, it was concluded that COVID-19 issue is complex to handle.

\section{Cyclomatic complexity}

The digraph (Figure 6) illustrates the factors affecting COVID-19 transmission and fatality. In particular, at level two, it shows complex interactions among the factors. This complexity can be described using cyclomatic complexity through digraph as: ${ }^{14}$

$$
M=E-N+2 p
$$

where

$E=$ the number of edges of the graph

$N=$ the number of nodes of the graph

$P=$ the number of connected components

The number of edges (depicted as arrows) shown in Figure 6 is 20, the number of nodes (depicted as rectangles) is 8 , and the number of connected components, $\mathrm{P}$ is equal to 1 . Then, the cyclomatic complexity $\mathrm{M}$ of the digraph given in Figure 6 is

$$
M=20-8+2 \times 1=14
$$

The tolerable upper bound that has been used for cyclomatic complexity is $10 .{ }^{14}$ Since the complexity of the COVID-19 through digraph shown in Figure 6 gives a complexity of 14, we can conclude that it is difficult to grasp the complexity of the COVID-19 situation.

\footnotetext{
${ }^{14}$ McCabe, T. J. (1976). Describing Cyclomatic Complexity, IEEE Transactions on Software Engineering, Vol. 2, No. 4, p. 308.
} 
As seen from Figure 6, the issue of COVID-19 transmission and fatality consists of multiple levels of combinations and functional behaviors can arise at many of the levels. It is normally difficult in dealing with complex issues such as this one. The complexity of the COVID-19 transmission and fatality is due to the existence of many factors and interactions among them. The existence of interacting factors complicates the solution of the problem which may or may not be explained clearly. However, the understanding of COVID-19 is evolving.

We can think about these eight factors shown in Figure 6 as the performance measures to control the spread of the COVID-19. Since a large number of edges enter and leave the factors in level 2, four main important factors, person to person contact (measure 1), indirect transmission (measure 3), underlying health condition (measure 4), and worldwide traveling (measure 5) shown in Figure 6 are the most critical factors which need to be considered first to control the spread of the virus that causes COVID-19. These four factors not only affect but also are affected by the other factors.

As shown in Figure 7, all performance measures of factors affecting COVID-19 transmission dynamics have been classified into four categories. Cluster I includes autonomous factors. As seen from this figure, they have low driving power and low dependence, hence they can be eliminated from the consideration of COVID-19 spread in the model. For this case, no factor has been identified as an autonomous factor, therefore all these identified factors influence and shape the outcome of COVID-19 spread.

Cluster II includes dependent factors that have low driving power and high dependence. As seen from Figure 7, only the economic dimension (measure 6) is positioned in this cluster. As shown in Figure 6, factor economic dimension is positioned at the top of the hierarchy - affected by all the other factors. It has very little driving power but very high dependency. In other words, the COVID-19 transmission and fatality due to the existence of many factors and their interactions created disasters and consequently resulted in an economic shutdown.

The factors in the linkage cluster III should be given extreme consideration due to their high driving power and high dependence power. Cluster III includes linkage factors of person-to-person contact (measure 1), indirect transmission (measure 3), underlying health conditions (measure 4), and worldwide traveling (measure 5). These key factors affect and depend on other factors in COVID-19 spread and fatality. The four major factors in this cluster must be carefully managed.

Cluster IV includes the independent factor of behavior (measure 2) and availability of testing (measure 7) with a moderate drive power but very week dependence. These two factors are controlled and derived by the government (measure 8) which has a strong drive power. This factor (government) is the key driver for the COVID-19 transmission and fatality dynamics.

\section{Conclusion}

In conclusion, the complexity of COVID-19 was investigated through Interpretive Structural Modeling (ISM). The student research team developed transdisciplinary collective intelligence using the Interactive Collective Intelligence Management (ICIM) workshop to investigate the issue of the COVID-19. It is important to note that this workshop was repeated three times in three different times. During the iterative Interactive Collective Intelligence Management, research team has generated numerous of scenarios to address the COVID-19 issue - more than 75 different problem areas were identified and discussed. After openly discussing conflicting ideas, heavily dialogue and debate, the research team identified eight main factors out of twenty four affecting the complexity of the issues surrounding COVID-19.

Two different approaches were used to describe the complexity of the COVID-19 issue. (a) the Situation Complexity and (b) Cyclomatic complexity. When analyzing situation complexity of a complex issue of COVID-19 solving in teams, varying perceptions among the team members were noticeable. That is why ICIM was repeated three times. Both approaches revealed that the complexity of the COVID-19 issue is complex and difficult to handle the issue with routine approaches.

The digraph showed that the COVID-19 is a multilevel problem. The economic dimension, which was measure 6 , located at the top of the digraph as a result it was determined to be the most dependent factor 
A. Ertas, U. Gulbulak, K. Basel, M. Campos, G. Handley, D. Hebert, E. Melendez, F. Onatoye, O. Phearum, S. Sawadogo, J. Steckbeck, G. Tekell

The COVID-19 Crisis and Complexity in the United States

of the model. On the other hand, government regulations, the measure 8, was found to be the driving factor of the model.

\section{Acknowledgments}

The authors would like to thank all 32 students in the design class for their contributions to the interactive collective intelligence management workshop.

Contributions: All co-authors contributed equally.

Funding: This research received no external funding.

Conflicts of Interest: The authors declares no conflict of interest.

\section{References}

[1] André Dua, Deepa Mahajan, Lucienne Oyer, and Sree Ramaswamy, (2020). US small-business recovery after the COVID-19 crisis. https://www.mckinsey.com/industries/public-and-social-sector/our-insights/us-smallbusiness-recovery-after-the-covid-19-crisis (accessed January 5, 2020)

[2] https://www.cdc.gov/coronavirus/2019-ncov/need-extra-precautions/people-with-medicalconditions.html\#: :text=Adults\%20of\%20any\%20age\%20with\%20the\%20following\%20conditions $\% 20$ are $\% 20$ at, COPD\%20(chronic\%20obstructive\%20pulmonary\%20disease)

[3] Clark, A., Jit, M., Warren-Gash, C., Guthrie, B., Wang, H. H. X., Mercer, S. W., Sanderson, C., McKee, M., Troeger, C., Ong, K. L., Checchi, F., Perel, P., Joseph, S., Gibbs, H. P., Banerjee, A., Eggo, R. M., Nightingale, E. S., O'Reilly, K., Jombart, T., ... Jarvis, C. I. (2020). Global, regional, and national estimates of the population at increased risk of severe COVID-19 due to underlying health conditions in 2020: a modelling study. The Lancet Global Health, 8(8), e1003-e1017.

[4] https://www.mayoclinic.org/diseases-conditions/coronavirus/in-depth/coronavirus-who-is-at-risk/art20483301 (accessed February 26, 2021)

[5] https://www.the-scientist.com/features/how-social-isolation-affects-the-brain-67701 (accessed February 26, 2021)

[6] https://www.apa.org/monitor/2019/05/ce-corner-isolation (accessed February 26, 2021)

[7] Chu, D., Duda, S., Solo, K., Yaacoub, S., \& Schunemann, H. (2020). Physical Distancing, Face Masks, and Eye Protection to Prevent Person-to-Person Transmission of SARS-CoV-2 and COVID-19: A Systematic Review and Meta-Analysis. Journal of Vascular Surgery, 72 (4), 1500. doi:10.1016/j.jvs.2020.07.040

[8] Wang, J., Pan, L., Tang, S., Ji, J. S., \& Shi, X. (2020). Mask use during COVID-19: A risk adjusted strategy. Environmental Pollution, 266 , 115099. doi:10.1016/j.envpol.2020.115099

[9] Saidan, M. N., Shbool, M. A., Arabeyyat, O. S., Al-Shihabi, S. T., Abdallat, Y. A., Barghash, M. A., \& Saidan, H. (2020). Estimation of the probable outbreak size of novel coronavirus (COVID-19) in social gathering events and industrial activities. International Journal of Infectious Diseases, 98 , 321-327. doi:10.1016/j.ijid.2020.06.105

[10] Mailonline, A. (2020, March 20). Half of Uruguay's coronavirus cases are traced to a single guest at a society wedding. https://www.dailymail.co.uk/news/article-8135413/Half-Uruguays-coronavirus-cases-traced -single-guest-society-wedding.html (accessed October 28, 2020)

[11] Beech, H. (2020, March 20). 'None of Us Have a Fear of Corona': The Faithful at an Outbreak's Center. https://www.nytimes.com/2020/03/20/world/asia/coronavirus-malaysia-muslims-outbreak.html (accessed October 28, 2020)

[12] Riddell, S., Goldie, S., Hill, A., Eagles, D., \& Drew, T. W. (2020). The effect of temperature on persistence of SARS-CoV-2 on common surfaces. Virology Journal, 17(1), 145.

[13] Ren, S. Y., Wang, W. B., Hao, Y. G., Zhang, H. R., Wang, Z. C., Chen, Y. L., \& Gao, R. D. (2020). Stability and infectivity of coronaviruses in inanimate environments. In World Journal of Clinical Cases, 8(8), 1391-1399 
[14] Herman, J., Biegel, B., \& Huang, L. (2021). Inactivation times from 290 to $315 \mathrm{~nm}$ UVB in sunlight for SARS coronaviruses $\mathrm{CoV}$ and $\mathrm{CoV}-2$ using OMI satellite data for the sunlit, Earth. Air Quality, Atmosphere 83 Health, 14(2), 217-233.

[15] Chin, A. W. H., Chu, J. T. S., Perera, M. R. A., Hui, K. P. Y., Yen, H.-L., Chan, M. C. W., Peiris, M., \& Poon, L. L. M. (2020). Stability of SARS-CoV-2 in different environmental conditions. it The Lancet Microbe, $1(1)$, e10.

[16] Shen, Y., Li, C., Dong, H., Wang, Z., Martinez, L., Sun, Z., Handel, A., Chen, Z., Chen, E., Ebell, M. H., Wang, F., Yi, B., Wang, H., Wang, X., Wang, A., Chen, B., Qi, Y., Liang, L., Li, Y., .. Xu, G. (2020). Community Outbreak Investigation of SARS-CoV-2 Transmission among Bus Riders in Eastern China. it JAMA Internal Medicine, 180(12), 1665-1671.

[17] Li, Q., Guan, X., Wu, P., Wang, X., Zhou, L., Tong, Y., Ren, R., Leung, K. S. M., Lau, E. H. Y., Wong, J. Y., Xing, X., Xiang, N., Wu, Y., Li, C., Chen, Q., Li, D., Liu, T., Zhao, J., Liu, M., .. Feng, Z. (2020). Early Transmission Dynamics in Wuhan, China, of Novel Coronavirus-Infected Pneumonia. it New England Journal of Medicine, 382(13), 1199-1207.

[18] "WORLD TOURISM ORGANIZATION." 70\% Of Destinations Have Lifted Travel Restrictions, but Global Gap Emerging, UNWTO. www.unwto.org/news/70-of-destinations-have-lifted-travel-restrictions-but-globalgap-emerging. (accessed December 17, 2020)

[19] Evidence to recommendations: COVID-19 mitigation in the aviation sector, interim guidance. https://apps.who.int/iris/handle/10665/337134. (accessed November 27, 2020)

[20] "Promoting Public Health Measures in Response to COVID-19 on Cargo Ships and Fishing Vessels." www.who.int/publications/i/item/WHO-2019-nCoV-Non-passenger_ships-2020.1. (accessed February 26, 2021)

[21] van Doremalen, N., Bushmaker, T., Morris, D. H., Holbrook, M. G., Gamble, A., Williamson, B. N., Tamin, A., Harcourt, J. L., Thornburg, N. J., Gerber, S. I., Lloyd-Smith, J. O., de Wit, E., \& Munster, V. J. (2020). Aerosol and Surface Stability of SARS-CoV-2 as Compared with SARS-CoV-1. it New England Journal of Medicine, 382(16), 1564-1567.

[22] Jamison, J. C., Bundy, D., Jamison, D. T., Spitz, J., \& Verguet, S. (2020). Comparing the impact on COVID-19 mortality of self-imposed behavior change and of government regulations across 13 countries. it medRxiv, 2020.08.02.20166793

[23] Mendolia, S., Stavrunova, O., \& Yerokhin, O. (2021). Determinants of the community mobility during the COVID-19 epidemic: The role of government regulations and information. it Journal of Economic Behavior \& Organization, 184, 199-231.

[24] Parmet, W. E., \& Sinha, M. S. (2020). Covid-19 — The Law and Limits of Quarantine. it New England Journal of Medicine, 382(15), e28.

[25] Xie, Q and Coffey, H. Canary Islands holidays: What are the latest travel rules and do you need a Covid test? https://www.yahoo.com/lifestyle/canary-islands-holidays-latest-travel-113742542.html (accessed February 26, 2021)

[26] Watson, J., Whiting, P. F., \& Brush, J. E. (2020). Interpreting a covid-19 test result. it The BMJ, 369.

[27] Normille, D. Why airport screening won't stop the spread of coronavirus. https://www.sciencemag.org/news/2020/03/why-airport-screening-wont-stop-spread-coronavirus (accessed February 26, 2021)

[28] Zitek, T. (2020). The appropriate use of testing for Covid-19. it Western Journal of Emergency Medicine, 21(3), 470-472.

[29] Reliable COVID-19 test could reduce virus spread. https://www.eurekalert.org/pub_releases/2020-12/arurct121620.php (accessed February 26, 2021)

[30] Wan, W. How do home tests for coronavirus work? Where can I get one? https://www.washingtonpost.com/health/2020/12/16/coronavirus-home-test-rapid (accessed February 26, 2021)

[31] Pak, A., Adegboye, O. A., Adekunle, A. I., Rahman, K. M., McBryde, E. S., and Eisen, D. P. (2020). Economic Consequences of the COVID-19 Outbreak: The Need for Epidemic Preparedness. Front. Public Heal., 8, 19. 
A. Ertas, U. Gulbulak, K. Basel, M. Campos, G. Handley, D. Hebert, E. Melendez, F. Onatoye, O. Phearum, S. Sawadogo, J. Steckbeck, G. Tekell

The COVID-19 Crisis and Complexity in the United States

[32] Nicola, M., Alsafi, Z., Sohrabi, C., Kerwan, A., Al-Jabir, A., Iosifidis, C., Agha, M., and Agha, R., (2020). The Socio-Economic Implications of the Coronavirus Pandemic (COVID-19): A Review, Int. J. Surg., 78, $185-193$.

[33] USDA ERS - Farms and Farm Households During the COVID-19 Pandemic. https://www.ers.usda.gov/covid19/farms-and-farm-households/ (accessed January 18, 2021)

[34] Cai, M., and Luo, J. (2020), Influence of COVID-19 on Manufacturing Industry and Corresponding Countermeasures from Supply Chain Perspective, J. Shanghai Jiaotong Univ., 25(4), 409-416.

[35] COVID-19 and the Aviation Industry: Impact and Policy Responses. http://www.oecd.org/coronavirus/policyresponses/covid-19-and-the-aviation-industry-impact-and-policy-responses-26d521c1/ (accessed January 18, 2021)

[36] https://www.iata.org/en/iata-repository/publications/economic-reports/return-to-air-travel-expected-to-beslow/ (accessed January 18, 2021)

[37] Tourism and COVID-19 - Unprecedented Economic Impacts - UNWTO. https://www.unwto.org/tourismand-covid-19-unprecedented-economic-impacts (accessed January 18, 2021)

[38] Olympics Delay to Cost Japan $\$ 6$ bn in Economic Losses - Nikkei Asia. https://asia.nikkei.com/Spotlight/Tokyo2020-Olympics/Olympics-delay-to-cost-Japan-6bn-in-economic-losses (accessed January 18, 2021)

[39] UEFA's Biggest Challenge of the Coronavirus Crisis: Easing the Economic Impact on Clubs, Nations. https://www.espn.com/soccer/blog-marcottis-musings/story/4076049/uefas-biggest-challenge-ofcoronavirus-crisis-easing-the-economic-impact-on-clubsnations (accessed January 18, 2021)

[40] Modes of transmission of virus causing COVID-19: implications for IPC precaution recommendations. https://www.who.int/news-room/commentaries/detail/modes-of-transmission-of-virus-causing-covid19-implications-for-ipc-precaution-recommendations (accessed February 1, 2021)

[41] https://www.webmd.com/lung/coronavirus-transmission-overview (accessed February 1, 2021)

[42] https://www.thelancet.com/action/showFullTableHTML?isHtml=true\&tableId=tbl1\&pii=S0140$6736 \% 2820 \% 2930607-3$ (accessed February 1, 2021)

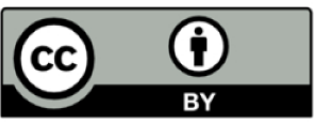

Copyright (C) 2021 by the authors. This is an open access article distributed under the Creative Commons Attribution License (https://creativecommons.org/licenses/by/4.0/), which permits unrestricted use, distribution, and reproduction in any medium, provided the original work is properly cited.

\section{About the Authors}

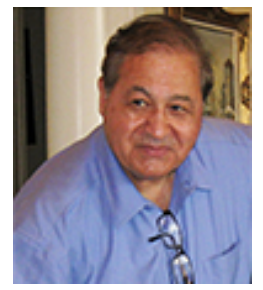

Dr. Atila Ertas, advisor of this project is a professor of Mechanical Engineering at Texas Tech University. Dr. Ertas has many years of experience in teaching transdisciplinary design courses. He is the author or co-author of over 190 technical papers that cover many engineering technical fields. He is the author of many research and textbooks on interdisciplinary and transdisciplinary studies. 


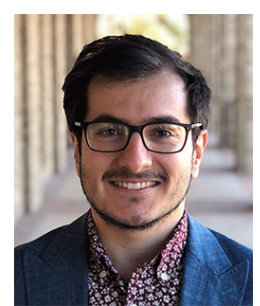

Dr. Utku Gulbulak, advisor of this project received his BS degree in Mechanical Engineering from Middle East Technical University, Turkey in 2014 and his PhD in Mechanical Engineering at Texas Tech University in 2020. His primary research interest is the parametric design of artificial heart valves using multiphysics modeling and machine learning. His secondary research interest is the impact of transdisciplinary education on the engineering discipline.

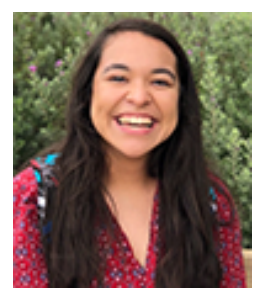

M. Campos is from Fort Worth, Texas. She is a senior undergraduate mechanical engineering student at Texas Tech University. She is one of the student research team member.

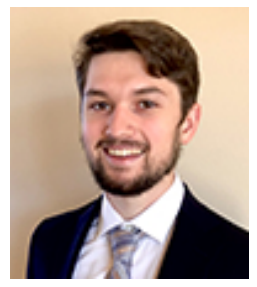

G. Handley is a senior undergraduate mechanical engineering student at Texas Tech University. He is one of the student research team member.

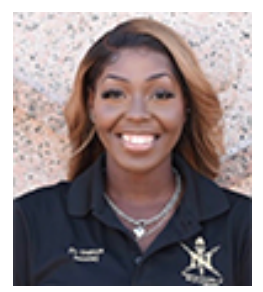

F. Onatoye is a senior undergraduate mechanical engineering student at Texas Tech University who is minoring in mathematics. She is one of the student research team members.

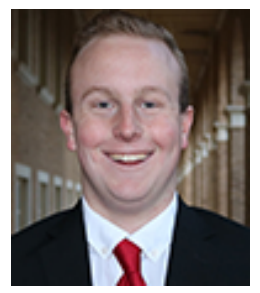

J. Steckbeck is a senior undergraduate mechanical engineering student at Texas Tech University. He is one of the student research team member. 
A. Ertas, U. Gulbulak, K. Basel, M. Campos, G. Handley, D. Hebert, E. Melendez, F. Onatoye, O. Phearum, S. Sawadogo, J. Steckbeck, G. Tekell

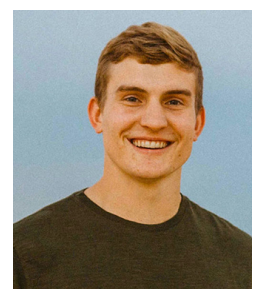

G. Tekell is a senior undergraduate mechanical engineering student at Texas Tech University who is minoring in Chemistry due to his interest in the medical field. He is one of the student research team members.

K. Basel, D. Hebert, E. Melendez, O. Phearum, S. Sawadogo are senior undergraduate mechanical engineering students at Texas Tech University. They are student research team members. 